\title{
MICROMECHANICS OF FORMATION OF A QUARTZO- FELDSPATHIC SHEAR ZONE
}

G.E. Iloyd,

Department of Earth sciences, The University, Leeds, England and Centre Geologique et Geophysique, U.8.T.I., 34060 Montpellier Cedex, France. D. Mainprice, Laboratoire de Tectonophysique, U.S.T.I., 34060 Montpellier Cedex, France. R.D. Law, Dept. Geological sciences, V.P.I.S.U., Blacksburg, Virginia 24061, USA. J. Wheeler, Dept. Earth sciences, University of Liverpool, PO Box 145, Liverpool, England.

We have investigated a $30 \mathrm{~cm}$ wide dextral shear zone (Fig. 1) in a quartzo-feldspathic vein (Torridon, NW Scotland). The high shear strain regions show the classic microstructures and textures $^{1}$ associated with increasing simple shear deformation ${ }^{2}$. We have used SEM techniques ${ }^{3-4}$ to investigate the micro-mechanics of formation of this shear zone. Discontinuous feldspar bands (Fig. 1) have been used to estimate relative shear strain. SEM electron channelling (EC) images illustrate a variety of initial microstructures. Most can be considered in terms of increasing shear strain. Their origin is central to the micro-mechanics of shear zone formation.

LOW SHEAR STRAIN MICROSTRUCTURES

Considerable variation in intragranular microstructures occurs between individual grains (Fig. 2). SEM/ECP analysis of three adjacent grains suggests that they have responded differently to deformation (Fig. 3). The crystal 
axes of the first grain are increasingly dispersed towards the primitive, consistent with rotation about the specimen $\mathrm{Y}$-axis. The second grain exhibits crystal axis dispersions consistent with slip on a basal-m system. In the third grain the positions of the $r$ and $z$ axes are frequently interchanged, consistent with a twinning process.

The complexity of intragranular deformation is shown by plotting (Fig. 4) the $\psi_{1}$ and $\varnothing$ euler angles ( $\phi_{2}$ is constant) for the first grain (Fig. 2). A "core" of larger subgrains close to the parental orientation, is surrounded by a "mantle" of smaller subgrains with larger misorientations. A surface "veneer" of subgrains showing a consistent change in orientation relative to the core and mantle, is separated from the mantle by a narrow intragranular "shear band" consisting of elongate subgrains. These relationships are consistent with grain rotation about the specimen Y-axis (Fig. 3a) and suggest that shear strains are concentrated in the vicinity of grain boundaries (the adjacent grain shows intense grain size reduction). The variation of deformation across grain boundaries accommodates the incompatibilities in deformation between grains.

\section{HIGHER SHEAR STRAIN MICROSTRUCTURES}

The different processes operating at low shear strains in general result in a progressive grain size reduction. However, a sudden and dramatic decrease in grain size occurs at higher shear strains. Considerable local variation in grain size often occurs across sharp boundaries. The crystal textures of these regions must reflect the early intragranular deformation histories. Sudden changes in crystal texture and apparently disparate textural elements are therefore likely to occur. The microstructural regions continue to develop with increasing shear strain, resulting in progressive grain size comminution and the modification of crystal textures. However, deformation continues to be localized along boundaries between microstructural regions, although many boundaries and microstructural elements may persist to high shear strains. 
The specimen includes only part of the central region of the shear zone, where shear strains are highest ${ }^{1}$. This microstructure consists of a fine $(\leqslant 10 \mu \mathrm{m})$ grain size, but changes in grain size still occur, usually across sharp boundaries. Although this microstructure appears to be stable, evidence exists for grain boundary migration (e.g. straight boundaries and $120^{\circ}$ triple junctions). Continuous, narrow (typically $<10 \mu \mathrm{m}$ ) bands, oriented parallel to the shear direction, of ultra-fine $(\leqslant 4 \mu \mathrm{m})$ grain size also occur and represent further localization of deformation.

\section{DISCUSBION}

Shear zone formation is inhomogeneous, and a variety of intragranular microstructures and crystal textures develop. This results in incompatibilities between grains and deformation localization along and/or adjacent to grain boundaries. Intragranular deformation may be similarly localized. The net effect is discontinuous grain size reduction and significant changes in grain size, microstructure and crystal texture occur across grain boundaries. Less significant changes occur across intragranular boundaries. Both types of boundary structure persist to higher shear strains, although the tendency for deformation to localize along them eventually leads to their disappearance via the formation of subgrains. These tend to migrate away from the boundaries and must ultimately meet other subgrains migrating from an adjacent boundary, resulting in the formation of a new boundary. Thus, a progressively increasing shear strain can be accommodated via the continuous recycling of a fine grain size microstructure, involving the repeated generation of deformation band boundaries and the localization of deformation along these boundaries. This process (which may appear as a stable grain size microstructure) is consistent with a grain boundary sliding deformation process (M.S. Patterson, pers. comm. 1990). Such a model for shear zone formation casts doubt over the validity of two established geological concepts: 1. recrystallized grain and/or subgrain size as a palaeopiezometer; and 2. interpretation of crystal 
textures and slip systems from bulk analytical techniques (e.g. X-ray texture goniometry).

\section{REFERENCES}

1. R.D. Law, S.M. Schmid and J. Wheeler, J. struct. Geol. 12, (1990).

2. A. Etchecopar, Tectonophysics 39, 121-139 (1955).

3. D.E. Joy and D.L. Newbury, J. Appld. Phys. 43, R88-R122 (1982).

4. G.E. Lloyd, Mineral. Mag. 41, 3-19 (1985).

5. N.H. Schmidt and N.O. Olesen, Canad. Mineral. 25, 14-22 (1989).

6. G.E. Lloyd and B. Freeman, This Conference, (1990).

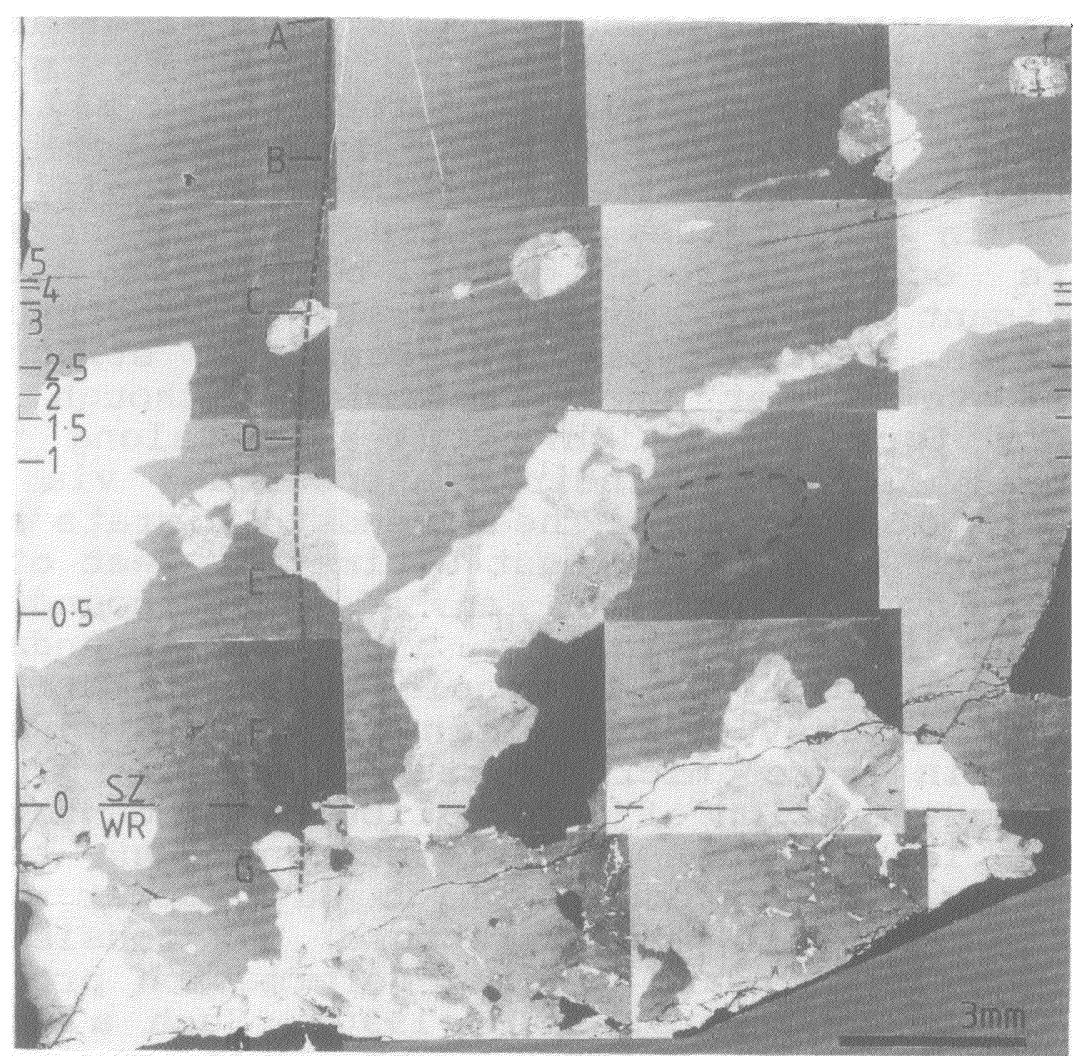

Figure 1. SEM Z-contrast montage of the shear zone; the bright contrasts are feldspar, the dark background is quartz. 


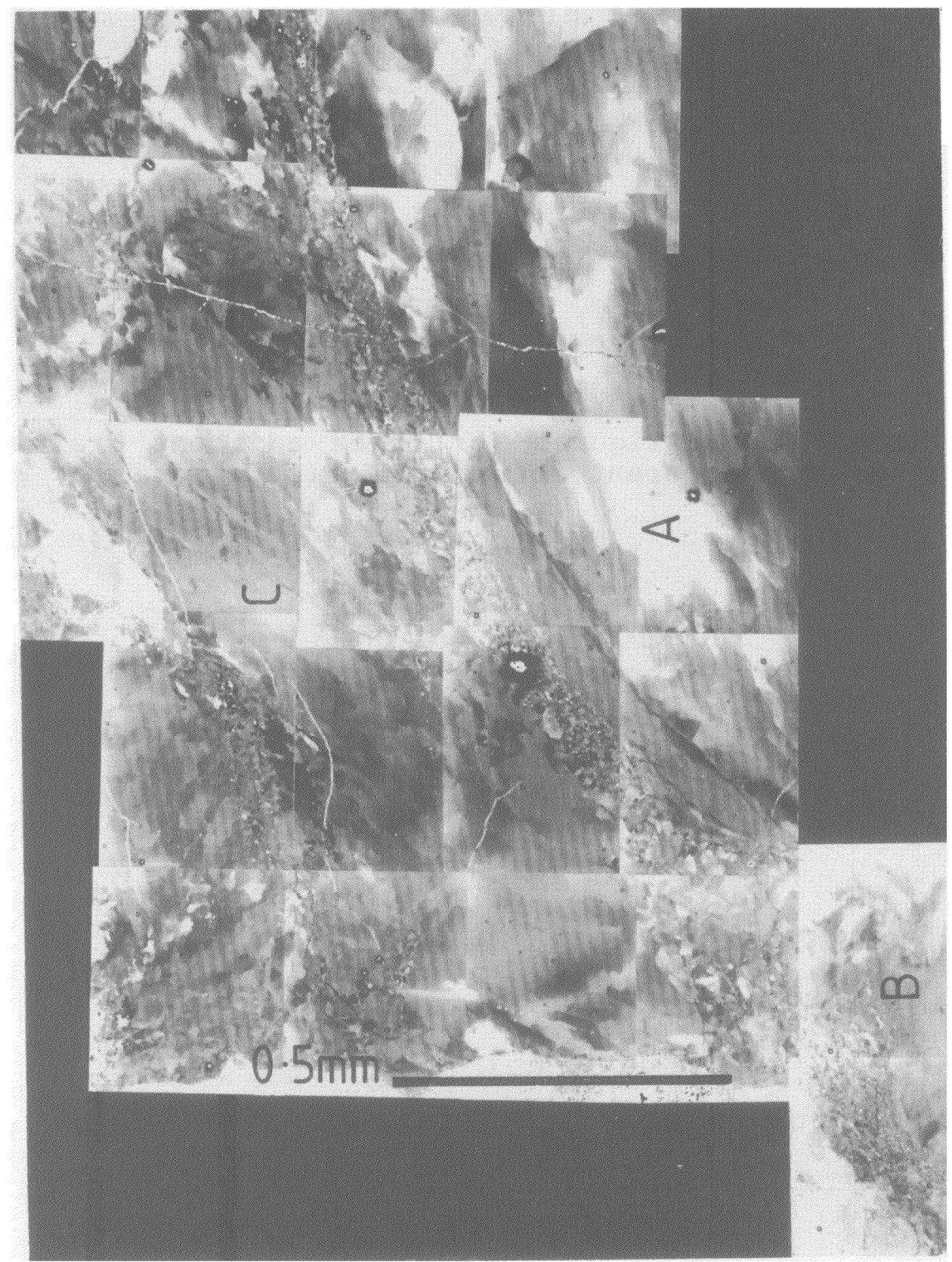

Figure 2. SEM/OC montage of adjacent grains close to the shear zone margin. See text for details. 
(a) GRAIN A

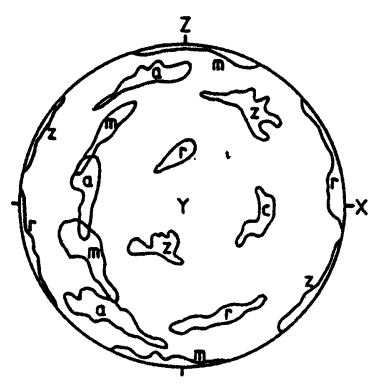

ROTATION ABOUT Y-AXIS (b) GRAIN B

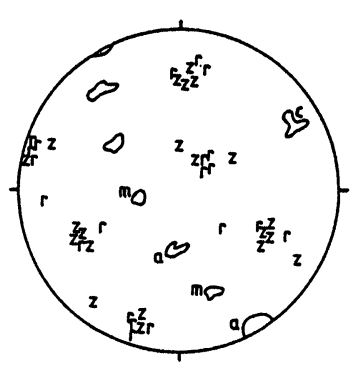

MECHANICAL TWINNING (c) GRAIN C

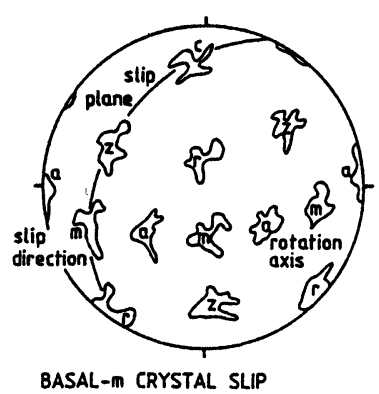

Figure 3. Pole figures for three adjacent grains indicating different intragranular deformations.

TORRIDON SHEAR ZONE: GRAIN A

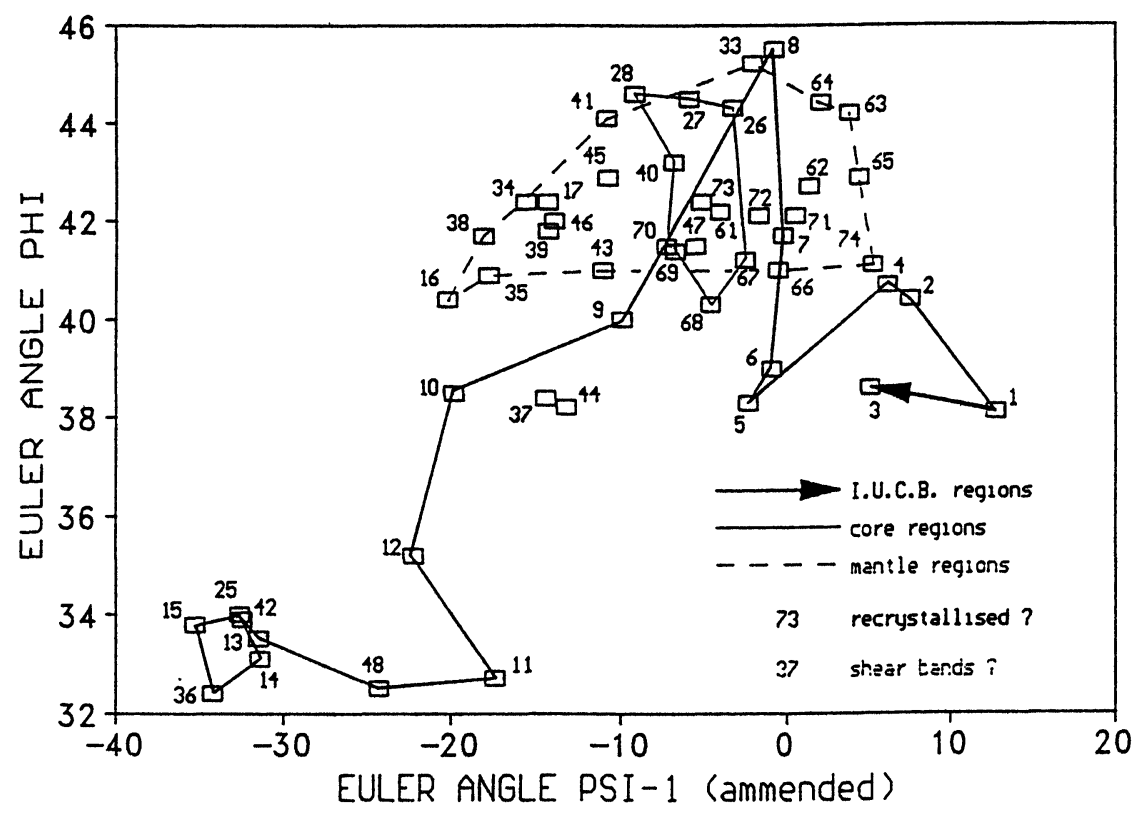

Figure 4. Plot of crystal euler angles $\phi$ and $\psi_{1}$, showing distinct microstructural regions. 